\title{
Fracture Characteristics of Random Oriented Glass Fiber Mats Composites
}

\author{
Y Yang $^{1}$, Tohru Morii ${ }^{2}$, H. Hamada ${ }^{1}$, \\ ${ }^{1}$ Division of Advanced Fibro-Science, Kyoto Institute of Technology, Kyoto 6068585, Japan, \\ 2) Shonan Institute of Technology, Kanagawa 251-8511, Japan \\ * Corresponding author (amy.yang@kit.ac.jp)
}

Keywords: mat, glass fiber, $\mathrm{AE}$, fracture, hole

Introduction Glass chopped fiber mats have been used as traditional reinforcements for fiber reinforced plastics. However, the number of literature is limited even long history. On the other hand, short fiber mats would be the suitable reinforcement configuration for natural fiber or filled composites because the natural fiber is inherently short fiber. Various fiber textile technologies can be used to fabricate the fiber mats structure, for example needle punching process, therefore the relation between different textile manufacturing techniques, the fiber mat structure and the composites properties should be fully understood. In this ICCM conference, there is an opportunity in short fiber reinforced composites session to introduce our recent improvements of short fiber mats reinforced plastic composites. This work sets out an in-depth investigation of fracture behavior of chopped glass mat reinforced composites using AE measurements by Dual AE measurement system using $140 \mathrm{KHz}$ and $1 \mathrm{MHz}$ sensors to understand the fiber and matrix fracture behaviors simultaneously [1]. Also the characteristic distance was calculated experimentally and was compared theoretically with the values obtained from finite element stress analysis. The obtained characteristic distance was evaluated based on the observation of crack during the progression of this crack.

Experimental 7 layers of glass chopped mat were laminated by hand-lay up molding method. The thickness of the composites was controlled about $4.4 \mathrm{~mm}$ to get a volume fraction of glass fiber around $21 \%$. To investigate the effect of the drill hole on the mechanical property on glass mat composite, a drill hole with a diameter of $10 \mathrm{~mm}$ in several specimens with different width were also prepared. The w/d i.e. the ratio of width to the diameter of the hole with the values of 2, 3 and 5 were used to discussed. The length is $150 \mathrm{~mm}$ for w/d ratios of 2 or 3 specimens while for $250 \mathrm{~mm}$ for w/d 5 specimen. During the tensile tests, acoustic emission (AE) was monitored simultaneously by 7600 series AE instrumentation (NF Corp., Japan). In AE measurement the transducers with the resonant frequencies of $140 \mathrm{kHz}$ and $1 \mathrm{MHz}$ were attached onto those points with a distance of $10 \mathrm{~mm}$ from the drill-hole along the longitudinal axial direction of the specimen. The fixed gain was $40 \mathrm{~dB}$ and the threshold was set at $100 \mathrm{mV}$ to avoid the inclusion of noise.

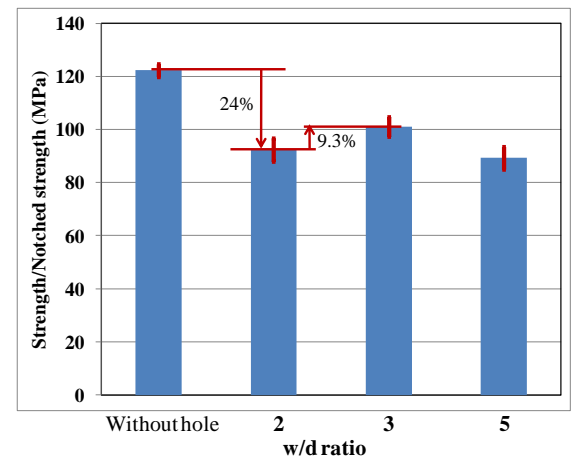

Fig. 1 Strength v.s. Notched strength

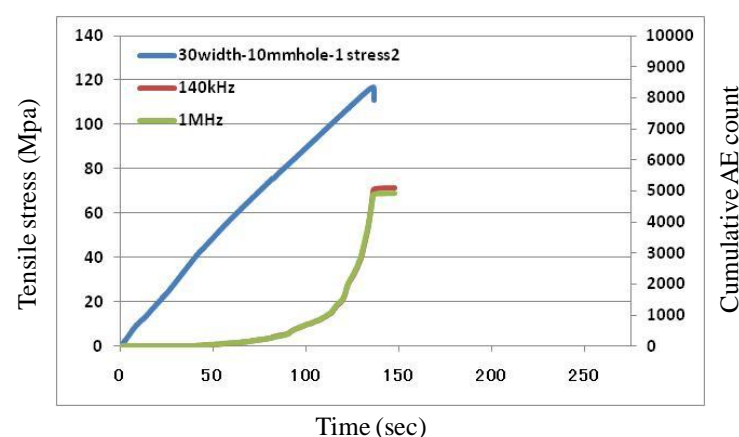

Fig.2 Stress and cumulative AE counts - time curves of glass mat composite with a drill-hole

Conclusion As shown in Figs $1 \& 2$, it is found that the notched strength decrease by drilling a hole in the center. While regarding to the effect of w/d ratio, w/d of 3 specimen seems to have relative higher notched strength as compared to 2 or $5 \mathrm{w} / \mathrm{d}$ specimens. The fracture characteristics during the tensile test studied by AE show that AE single came out almost at the same time which detected by both $140 \mathrm{kHz}$ and $1 \mathrm{MHz}$.

\section{References}

(1) T. Morii, N. Jumonji, T. Fujita and H. Hamada, Book of Abstracts of the Asian Workshop on Polymer Processing 2007, 2007, 112. 